\title{
Influence of the Internet on Studying English
}

\author{
Irma Igorevna Molchanova ${ }^{1}$ \\ ${ }^{1}$ Peoples' Friendship University of Russia, Moscow, Russia \\ Correspondence: Irma Igorevna Molchanova, Peoples' Friendship University of Russia, Ordzhonikidze st. 3, \\ Moscow, Russia.
}

Received: September 19, 2014 Accepted: October 27, 2014 Online Published: December 30, 2014

doi:10.5539/ies.v8n1p133

URL: http://dx.doi.org/10.5539/ies.v8n1p133

\begin{abstract}
The article considers theoretical aspects of influence of the Internet on studying English, including on the opportunities of listening and increase of motivation for studying English. The characteristic of blended learning technology in studying the foreign languages is given. The practical justification of the efficiency of studying English using the information-communicative technologies, in particular the electronic and communication learning platform Moodle in the process of implementation of blended learning technology is presented. The efficiency and motivating influence of use of the information-communicative technologies in the educational process is experimentally shown.
\end{abstract}

Keywords: listening, intrinsic motivation, extrinsic motivation, blended learning, subject-subject interaction, electronic-communicative learning platform

\section{Introduction}

Today the Internet provides a wide range of opportunities associated with different aspects of education. Currently, the global network allows us to get higher education, to study a foreign language at option, to refresh the acquired long ago knowledge.

As for studying a foreign language, by means of the Internet it is possible to improve the language skills considerably as well as to learn it practically from scratch. It is feasible by means of special services which allow not only to learn a language online but also to contact to the native speakers, to watch videos in a studied foreign language with the necessary comments on the lexical structure of a video.

On the whole, all the totality of the opportunities of the Internet in studying a foreign language can be distinguished into the following groups:

1) Language lectures and lessons containing new vocabulary, explaining any grammatical structures with exercises on fixing a studied material;

2) Determination of the level of proficiency of a foreign language and control of acquisition of new knowledge using the available online language tests;

3) Watching video and listening to audio in a foreign language with the further analysis of the language features in it such as the grammatical structures, phraseological units, complex phrases and slang features;

4) Direct communication with the native speakers or other Internet users, studying a foreign language, which allows to master the colloquial speech more effectively and perceive a foreign language aurally better.

\section{Theoretical Part}

Formation of the foreign-language communicative competence is defined today as the main objective of teaching a foreign language in the higher education institution what assumes formation of the foreign-language speech in the communicative activity.

Recently a question of application of new information technologies in studying the foreign languages is becoming urgent. In the specified context it is related not only to new technical means but also to new forms and methods of teaching, new approaches to the educational process.

For today a huge number of computer programmes, intended for use in studying English, has been created, among which there are rather successful ones but in the majority, however, they are useless and do not give any advantages of use of the information technologies. 
All the programmes, intended for studying English, have one common disadvantage: the amount of the educational material, put in them, is very limited and in spite of the fact that the course of studying English can be called full, and the programme itself-very successful and effective, nevertheless, the amount of the educational material, put in the programme, does not give opportunities for achieving the level of English fluency (Clarke, 2004).

In this regard, as the sizes of the Internet resources are really huge the Internet gives the unlimited opportunities for studying English. The global network provides the unlimited amount of teaching materials, including any significant information, materials on regional geography, newspaper and journal articles, educational literature, etc.(Peachey, 2012).

In recent years the researchers pay close attention to various aspects of influence of the Internet on studying English: motivation (Petrovskaya, 2014; Fufurina, 2014), technological (Rymanova, 2013; Malinina, 2014) and didactic peculiarities (Kostina, 2010; Azevich, 2012).

In studying the English language on the basis of the materials, put on the Internet, a number of educational tasks is solved: formation of abilities and skills of listening, reading, writing, increase of vocabulary and also formation of learners' steady motivation for studying language.

The main objective in studying English within a competence-based approach is formation of the communicative competence what means formation of communication skills and abilities for cross-cultural interaction, being a basis for functioning of the Internet.

As behind communication the global network loses the most part of its meaning as, in fact, the Internet is an international, multinational, cross-cultural community which functioning is based on the communicative interaction by means of electronic communication of millions of people around the world using the appropriate Internet resources (social networks, e-mail, TV and video conferences, etc.).

Communication in the natural language environment, which provides the Internet, allows to appear in real life situations. Involvement in a wide range of international communication leads to spontaneous mastering a foreign language, to stimulation for formation of original formulations and statements not to sample manipulation of language formulas. At that a learner's main efforts are directed to understanding, reproduction of the contents and expression of sense what leads to strengthening of motivation for studying of structure and dictionary of the English language serving for these purposes. As a result, the learners' attention is focused on the use of linguistic forms than on their thoughtless memorizing and studying grammar happens indirectly, in direct communication, leaving behind abstract learning grammatical rules.

Mastering the communicative and cross-cultural competences is impossible out of direct communication and, therefore, the Internet resources use is irreplaceable in studying English in this aspect as the Internet gives the users opportunities for authentic communication with real interlocutors on subjects in which both parties are interested.

Besides, the fact, that in the last some years a very perspective and effective trend has been formed all over the world-communication with native speakers in a format of a language tandem or independent studying each other's languages by two multilingual partners in a situation of real or virtual communication, has become of great importance in the field of direct communication with native speakers or other people studying languages. Thus, the purpose of each of two participants of the language tandem is mastering the partner's language by acquaintance with his personality, culture and traditions of his country and also communication on various topics of conversation with the native speaker. The special websites, such as International linguistic community (http://lingcom.ru/index.php?l=ru), SharedTalk (http://www.sharedtalk.com/), etc., have been created for the language tandem.

At that perception of a foreign language aurally becomes one of stumbling blocks. Previously, this was due to shortage of qualitative materials on English listening to get which was very difficult at all in far Soviet period. Today the Internet has washed out the informational borders between the states and the English audio has become available. To listen to English online is not a problem now and the necessary materials for English listening can be received in the Internet easily.

But using the Internet the problem has not disappeared completely and it is concluded in the fact that to study on the materials, loaded for English listening, is not always easy.

Thus, the English audio recordings quite often are without a transcript and to listen to the English audio without a transcript for a person, who has not heard the English language before and has learnt English words by the English transcription in the best case, is not easy (Azevich, 2012). 
In spite of the fact that today it is easy to find and listen to the English audio with a transcript, there are still some problems as such English audio with a transcript is usually done by English speakers and most often there are no translations to such English texts. If there is much new vocabulary and there are idioms in an English text it is not easy to understand such English audio. One has to look for the translation of words but it does not always help to understand the meaning of idioms.

Also, unfortunately, there are no printouts for the vast majority of the English audio recordings, put on the Internet. In other words, in the process of such English listening a learner has no an opportunity to verify speech with an English text and if he does not catch something in the process of listening, this part of an English audio recording may remain a riddle for him forever, causing a dissatisfaction feeling, and belittling belief in his own language abilities(Cohen, 2005).

In the case when one succeeds in finding the English audio recordings with printouts of the text for listening, the difficulties do not end there. Now a language learner faces a necessity to resort to services of the English dictionary, to decipher meanings of some set or slang expressions and also feels dissatisfaction again because of impossibility once again to listen to some English phrases difficult for him. In this regard, some have to listen to the same English audio recording repeatedly what is not a good way out of the current situation, as most often not all the text arouses interest but only some phrases and sentences. Thus, a language learner has to spend a considerable amount of time on repetition of the parts of the English text, unnecessary for him, what leads to the fall of intensity of English listening classes.

However, the modern computer technologies brought long-awaited innovations in English listening. Today in many programmes, put on the Internet, sentence-by-sentence synchronization of a text and audio with an opportunity to play any part of a text at option has become available. English listening started to become comfortable at last.

However, according to the researchers, most programmes, working with synchronized texts, have some disadvantages. Thus, some of them can brighten a played fragment but give an opportunity to reproduce an English text only from the very beginning. Other programmes do not provide an opportunity to interrupt playing in asounding of the English sentences. And such a necessity arises often. Quite often a process of start of playing is organized uncomfortably as one has to choose a necessary English sentence at first and only then to start it by pressing a button. At that to choose a necessary sentence one has sometimes to press the button "forward/back" repeatedly in order to pass to the necessary part of the text, though it would be more natural and comfortable to organize a choice and start of playing of the necessary fragment of the English text by way of a simple click of a mouse in the necessary part of the text (Kulhavy, 2007).

Thus, ideally, to listen to the English language online with the greatest benefit and the least loss of time the English audio must have both a transcript and translation into Russian.

In our opinion, to more effective use of studying English leads providing the following opportunities of listening. Firstly, synchronization of audio with text and translation is necessary for more comfortable listening of the English audio. That is, when listening to the English audio, one should brighten an English text, played at the current moment, and show a translation of the played fragment. Due to it, when listening to the English audio, there is no need to look after an English text all-time. A learner can turn his eyes freely to a position, comfortable for concentrated perception of the English language aurally, and if necessary, when something is not clear, return his eyes to an English text and find a necessary part played at the current moment without any effort.

Secondly, in addition to the English text itself, it is necessary to asound each separate word in the text. It allows to listen to English online not only more comfortably but also more qualitatively. In live speech words are often merged and sometimes are even swallowed. Therefore, it is necessary to give an opportunity to listen to a fragment, which sounds not distinctly for a user, by words, and then to try to catch everything aurally entirely again.

Thirdly, it is desirable to translate not only the text but also each word in the text. In many cases to translate an English sentence into Russian literally, not losing its meaning is impossible. In this situation the translation of words helps to understand the meaning of each word in the sentence, to realize its role.

With the listed opportunities listening to the English audio becomes really pleasant and comfortable.

Not less influence in studying English the Internet has on formation of learners' steady motivation for studying language.

In the modern era, characterized by globalization of all spheres of life of society, the motivation problem in 
studying a foreign language becomes extremely urgent. Globalization leads to more and more increasing role of interpersonal contacts and, as a result, verbal communication is becoming of special importance, including international one requiring mastering a foreign language. Mastering the foreign languages is becoming one of the leading factors of social-economic and common cultural development of society. Mastering a foreign language plays a major role in the process of a personality's formation and education level increase as with its help receiving of direct access to spiritual wealth of other countries is realized, direct communication with representatives of other people is implemented. In this regard, the growth of interest to studying the foreign languages, mainly, English which mastering has become an undoubted attribute of a modern highly educated personality, is not surprising. Mastering a foreign language has turned into the real requirement as getting of a prestigious job and career growth is almost unreal without it. Striving of our state to active and effective cooperation with other countries has affected strengthening of the importance of the subject "foreign language" considerably and made rethink the purposes, tasks and contents of studying the foreign languages. The specified above raises prestige of the subject "foreign language" considerably as an educational discipline in the higher education institution. In this regard, motivation for studying a foreign language moves to the forefront.

According to Passov's (1991) classification, intrinsic and extrinsic motivation is distinguished in studying a foreign language.

The so-called broad social motivation and also the personal motivation, connected with perspective of the personality development, belong to extrinsic motivation. As Petrovskaya and Rymanova's (2014) research of motivation for studying a foreign language in the Higher Professional Education Establishment shows, 34\% of the respondents indicated a potential opportunity to communicate with foreign colleagues on professional questions via the Internet in the future. This factor belongs to the motivation, connected with perspective of the personality development, namely, to formation and development of the professional competences.

But in aspect of our research intrinsic motivation is of great interest to which communicative motivation and also motivation, generated by actually educational activity (operational and tool motivation), are referred (Malinina, 2014).

The results of the same Petrovskaya and Rymanova's (2014) research also show that within communicative motivation communication with use of the modern information technologies (chats, forums, e-mails, etc.) plays a crucial role; $55 \%$ of the respondents pointed out to this component of communicative motivation in studying English. In aspect of operational-tool motivation 58\% of the respondents study English in order to have an opportunity to look through the scientific texts and articles in original language on their specialties on the Internet, presented in a greater number in English. In this regard, it is established by the research that students often stop their choice on elective courses, namely, courses of professional English. Besides, availability of Wi-Fi zones in an educational institution also creates favourable and attractive conditions for studying English.

The research, conducted by Fufurina (2014), held at MSTU named after Bauman, has confirmed the results of the previous research and has shown the predominance of intrinsic motives over extrinsic ones in studying English. So from the motives, offered at option, the majority of the students (32\%) study English to get acquainted and communicate with English-speaking interlocutors on the Internet via correspondence or conversations by Skype. At that a priority for them is overcoming a language barrier in communication. So the motive of communicative communication takes a first place.

Not less important motives, on which the Internet has influence, are motives of understanding language broadcasted in the Internet videos (movies, TV programmes, clips, entertaining shows) to which more than 15\% of the respondents pointed, motives of mastering computer programmes (about $9 \%$ of the respondents) and of understanding authentic texts (about $6 \%$ of the respondents) put on the Internet.

Today many researchers come to a conclusion that intrinsic motivation for studying a foreign language is supported and developed by such measures as application of modern methods of teaching, including communicative-activity method, focused on the student, and also the information-communicative technologies one of which is so-called blended learning (Malinina, 2013).

The last notion of blended learning has arisen relatively recently. In Kostina's (2010) opinion, as blended learning should be understood a system of teaching combining the most efficient aspects and advantages of in-class teaching and interactive or distance learning; i. e. a system, consisting of various parts functioning in stable relation with each other, forming an effective whole.

In realization of blended learning studying a discipline online joins traditional teaching a subject (in our case, English) passing according to the schedule. At that learning is blended only provided that for studying a 
discipline online, according to one data, not less than $45 \%$ of the educational process (Tomlinson \& Whittaker, 2013), another-from 30 to $79 \%$ (Watwood, Nugent, \& Deihl, 2009) is given, with obligatory in-class communication of a teacher and students.

According to the researches (Malinina, 2013), blended learning in studying English is effective for senior students as it leads to optimization of the educational process of students busy in implementation of projects and studying disciplines in direct specialties, gives opportunities for effective organization of their self-guided work by means of the information technologies and electronic-communication educational covers.

\section{Methods}

For realization of blended learning we have applied the modular object-oriented dynamic educational environment Moodle created as an Internet product for free distribution by the developers. Alternatively this cover is called Course Management System, Learning Management Systems or Virtual Learning Environment (Gaynor, 2011).

Platform Moodle was developed for creation of on-line courses with maximum interactivity of participants (teacher and students). Moodle includes a flexible designer of tests allowing supplying courses with online-tests to test learners' knowledge. The system provides giving roles to the users and the basic roles "Administrator", "Author of a course", "Teacher of a course", "Student", "Probationer", "Guest" and "Authorized user" are defined (Cohen, 2004).

From the pedagogical point of view, the philosophy of Moodle is based on the ideas of constructivism and social-constructivist approaches to education. In practice it means that each learner and not only a teacher can make his active contribution to the general educational field of active accumulation and acquisition of knowledge and also acquisition of necessary knowing how in various ways. To implement such an approach platform Moodle is supplied with various modules which facilitate collaborative work in groups and individually what allows a teacher and students to be in a continuous interactive dialogue, to conduct assessment and self-assessment and also fixes active participation in the work of each participant. A student's status can be changed in the case of his successful achievements. A student can be chosen by a group as a tutor or assistant teacher, then his basic role in the course can be changed and he gets wider user rights of a resource (Rymanova, 2013).

It should be noted that blended learning increases the results of education, students acquire additional competences in work with information raising motivation at the same time. Formation of competences of planning and organizing educational strategy, development of abilities to autonomous education becomes a very significant result. At the same time the role of a teacher changes, the place of a traditional instructor is taken by an organizer, coordinator and moderator of the educational process (Azevich, 2012). A teacher starts acting not less important role of a partner and assistant who supports, directs and controls a student's informative activity consulting him. The effective organization of the educational process becomes one of the main teacher's tasks. Developing his teaching course a teacher sets the following tasks for himself:

Firstly, formation of educational-methodical supply of the course including definition of the main and additional teaching materials and also electronic resources for work in the classroom and out of it (Skibitsky, 2011);

Secondly, determination of types of speech activity and types of exercises for in-class and out-of-class work. Thus, the language exercises should be done independently in extracurricular time as, on the one hand, a lot of time is spent for them, and, on the other hand, senior students have abilities and skills, formed enough to work with different types of exercises to which imitative and permutation exercises, transformation exercises, expansion/reduction of sentences, matching synonyms, constructing phrases from the elements and others can be referred (Sergeeva, 2005). Students do these exercises independently, put in Moodle, by means of which a teacher moderates the educational process, in due time gives recommendations for doing tasks and also watches and controls students' self-guided work. In-class work consists generally of communicative activity during which students do mainly the speech exercises developing the communicative competences, first of all, in speaking aspect. Speech exercises may be consisted of question-answer exercises, retort exercises and also conditional conversation, retelling of the read texts, dramatization of a text or a communicative situation, description, discussion, oral telling. Professional-oriented education of students of technical and natural-science specialities assumes such communicative exercises as, for example, recoding information exercises (description of the geometrical figures, chemical reactions and formulas, schedules, technological processes, schemes of devices, etc. in English), oral speech (on results of studying some problem or summing up one's own research work), role-playing games (performance of various social and psychological roles, mastering communication in the conditions, close to reality as much as possible) (Romanov, Toroptsov, \& Grigorovich, 2000); 
Thirdly, implementation of control and self-control of students. At that the dynamic educational environment Moodle may become a motivating factor as it allows to organize the educational process accessibly, to create a logical structure of all its stages and to organize effective control for students (Malinina, 2014). Having mastered the processes of doing tasks, the users of Moodle realize perfectly that their work is regularly controlled by a teacher, who before the beginning of a class has already checked the done tasks and knows who of students has done his self-guided work at home and is prepared for efficient classwork. What becomes a motivating factor for students as they understand the tasks, set for them, and a finite aim of a class.

\section{Results and Discussion of Them}

Watching the students' activities during their work in the dynamic educational environment, holding conversations with them has testified that the used methodical supply of the process of studying English was psychologically comfortable, facilitated realization of their educational potential. The students gained confidence in their abilities, their learning activities quickened considerably, motivation for further learning appeared. Their self-guided work on the Internet led to the development of their intellectual spheres: to attention mobilization, perception and memory improvement. The students turned into the active initiators and controllers of their own self-guided learning work, the result of that was the increase of their self-awareness and self-assessment.

The questioning, aimed at identifying the students' willingness to use the Internet in the process of studying English, has showed a rather high level of both interest and assessment of usefulness of the information technologies application in the educational process.

The results of questioning are presented in Tables 1 and 2 .

Table 1.

\begin{tabular}{lccccc}
\hline & \multicolumn{5}{c}{ Importance scale } \\
\cline { 2 - 6 } & 1 & 2 & 3 & 4 & 5 \\
\hline before ICT application & $0 \%$ & $0 \%$ & $20 \%$ & $55 \%$ & $25 \%$ \\
after ICT application & $0 \%$ & $0 \%$ & $0 \%$ & $15 \%$ & $85 \%$ \\
\hline
\end{tabular}

Note: by importance scale "1" corresponds to the minimum value ("not important at all"), " 5 "-to the maximum value ("very important").

Table 2.

\begin{tabular}{lccccc}
\hline & \multicolumn{5}{c}{ Importance scale } \\
\cline { 2 - 6 } & 1 & 2 & 3 & 4 & 5 \\
\hline before ICT application & $0 \%$ & $10 \%$ & $15 \%$ & $50 \%$ & $25 \%$ \\
after ICT application & $0 \%$ & $0 \%$ & $5 \%$ & $35 \%$ & $60 \%$ \\
\hline
\end{tabular}

Note: by importance scale " 1 " corresponds to the minimum value ("not important at all"), " 5 " - to the maximum value ("very important").

According to the results, presented in Tables 1 and 2, the positive dynamics of the students' understanding importance and manifestation of their interest in studying English with application of the information technologies can be noted.

As it is known, the aim of studying professional English is formation of the communicative competence. In this regard, summing up and estimating the efficiency of the educational process as a form of final control the oral presentation of one's own research project with its subsequent discussion and debate was chosen, what gave the students opportunities to demonstrate the availability of both professional and foreign language communicative competence.

The term "communicative competence" was created by Hymes (1972), defining it as internal knowledge of situational propriety of language.

In the process of oral presentation the communicative competence was assessed by the following criteria:

- Building of an unfolded statement in the context of a communicative task and in specifically given volume; 
- Requesting and informing the necessary information;

- Argumenting of one's own point of view;

- Formulation of conclusions;

- Building of a logical and connected oral statement;

- Use of various strategies: description, argument, information, narration;

- Suggestions for discussion;

- Expression of one's own attitude to the considered problem;

- Exact and correct use of the language means of the statement framework.

In literature various classifications of the components of the communicative competence can be met. But many authors mention, as a rule, including such its parts (of the competence) as linguistic and sociolinguistic. As the main thing in ability to communicate in a foreign language should be considered, perhaps, mastering a language system of this language, that is the linguistic competence. Not casually the linguistic (or language) competence is put always on the first place in hierarchy of components of the communicative competence. The lexical competence is included into the structure of the linguistic (language) competence. In recent years the importance of lexis as a mean of communication has become paramount for researchers and teachers. The volume of vocabulary for formation of learners' foreign-language communicative competence has also an important role. In studying a foreign language in whole the lexical competence appears as the basic one.

In assessing the linguistic competence were taken into account:

- Correspondence of the used lexical units and grammatical structures to the contents of oral presentation;

- Correctness of the used vocabulary and grammatical structures;

- Variety of lexical word-combinations and grammatical means;

- Complexity of the used grammatical means.

The sociolinguistic competence means an ability to use the units of a language system of a foreign language in adequate communicative situations, in other words, an ability to competently and correctly use the lexical, grammatical, phonetic material in oral and written forms of the speech activity.

In assessing the sociolinguistic competence were taken into account:

- Observance of norms of English pronunciation;

- Correctness of stresses and into national framework of statements.

To analyse dynamics of the process of formation of the competences of foreign-language communication the "indicator of absolute increase" (A), representing the difference between the levels of competences (on a 10-point scale) before and after application of the information technologies in studying English and being calculated by the formula:

$\mathrm{A}=\mathrm{K} 2-\mathrm{K} 1$,

where K1-levels of competences before application of the information technologies;

K2-levels of competences after application of the information technologies.

The results of dynamics of the process of formation of the competences of foreign-language communication are presented in Table 3 .

Table 3.

\begin{tabular}{lccc}
\hline & $\begin{array}{c}\text { Communicative } \\
\text { competence }\end{array}$ & Linguistic competence & $\begin{array}{c}\text { Sociolinguistic } \\
\text { competence }\end{array}$ \\
\hline before ICT application & 5 & 5.5 & 4 \\
after ICT application & 9 & 8.5 & 8 \\
\hline
\end{tabular}

\section{Conclusion}

In the research process the positive influence of the information-communicative technologies and the Internet on 
the opportunities of studying English by students has been theoretically proved and practically confirmed. Besides the development of the language competences it has led to the increase of motivation for studying the language, degree of students' independence. Thus, the use of the information-communicative technologies and the Internet is pedagogically expedient, leads to optimization of the educational process.

The organization of the educational process with the use of a model of blended learning creates the favourable conditions leading to the integral development of a personality, to formation of the professional-significant competences, to what leads:

- Special the "subject-subject" nature of interaction of participants in the educational process;

- A learner's opportunity to do his self-guided work with necessary information;

- Creation and maintenance of the positive psychological atmosphere in the educational process;

- Organization of learners' address, corrected, controlled self-guided activities.

The way of organization of the educational process, the use of the specialized electronic environment, the subject-subject nature of interaction of a teacher and students and also forms and control means become the motivating factors in studying English by a model of blended learning.

The use of the educational electronic-communicative learning platforms, as a leading way of organization of the educational process, the partnership peculiarities of communication of a teacher and students increase the motivation for studying a foreign language, the better results become a consequence of that.

Thus, the use of the information-communicative technologies and the Internet in the educational process facilitates its humanization, gives an opportunity to realize the principles of personal-oriented learning in practice.

\section{References}

Azevich, A. (2012). Role of teacher's personal site in forming information learning environment. Modern scientific researches and innovations, 11. Retrieved August 28, 2014, from http://web.snauka.ru/issues/2012 $/ 11 / 18586$

Clarke, A. (2004). E-learning skills. Palgrave Macmillan.

Cohen, V. (2004). Interactive features in the design of videodisk materials. Educational Technology, 1.

Cohen, V. (2005). A reexamination of feedback in computer-based instruction: Implications for instructional design. Educational Technology, 1.

Fufurina, T. (2014). Ways of increase of motivation for studying the English language by students of MSTU named after N. Bauman. Humanitarian messenger, 1. Retrieved August 28, 2014, from http://hmbul.bmstu.ru/catalog/pedagog/engped/156.html

Gaynor, P. (2011). Effect of feedback delay on retention of computer-based mathematical material. Journal of Computer-Based Instruction, 8.

Hymes, D. (1972). On Communicative Competence. In J. Pride, \& J. Holmes (Eds.), Sociolinguistics. Harmondsworth: Penguin.

Kostina, E. (2010). Model of blended learning and its use in teaching foreign languages. News of higher educational institutions. Series: Humanities, 2(1), 141-144.

Kulhavy, R. (2007). Feedback in written instruction. Review of Educational Research, 47.

Malinina, I. (2013). Application of blended learning technologies in studying foreign language in higher school. Modern scientific researches and innovations, 10. Retrieved August 28, 2014, from http://web.snauka.ru/issues/2013/10/27936

Malinina, I. (2014). Monitoring and feedback implementing in web-related resources 2.0. Modern scientific researches and innovations, 1. Retrieved August 28, 2014, from http://web.snauka.ru/issues/2014/01/30565

Passov, E. (1991). Communicative method in teaching speaking foreign language. Series: Library of teacher of foreign language (2nd ed.). M.: Education.

Peachey, N. (2012). Web 2.0 tools for teachers.

Petrovskaya, T., \& Rymanova, I. (2014). Motivation for studying the English language by students of Technical Higher Education Establishment by blended learning. Philological sciences. Theory and practice questions. Gramota: in 2 parts, Part I, 7(37), 152-154. Retrieved August 28, 2014, from 
www.gramota.net/materials/2/2014/7-1/43.html

Romanov, A., Toroptsov, V., \& Grigorovich, D. (2000). Technology of distance learning in correspondence economic education system. M.: YUNITI-DANA.

Rymanova, I. (2013). Use of environment Moodle in learning professional foreign language by students of Technical Higher Education Establishment. Philological sciences. Theory and practice questions. Gramota: in 2 parts, Part II, 11(29), 164-167.

Sergeeva, M. (2005). New information technologies in English Language Teaching. Teacher, 2, 162-166.

Skibitsky, E. (2001). Didactic supply of DT process. Distance and virtual teaching, 1, 54-58.

Tomlinson, B., \& Whittaker, C. (2013). Blended Learning in English Language Teaching: Course Design and Implementation. London: British Council. Retrieved August 28, 2014, from http://englishagenda. britishcouncil.org/sites/ec/files/D057_Blended\%20learning_FINAL_WEB\%200NLY_v2.pdf

Watwood, B., Nugent, J., \& Deihl, W. (2009). Building from content to community: Rethinking the transition to online teaching and learning: A CTE White Paper. Virginia Commonwealth University: Center for teaching excellence.

\section{Copyrights}

Copyright for this article is retained by the author(s), with first publication rights granted to the journal.

This is an open-access article distributed under the terms and conditions of the Creative Commons Attribution license (http://creativecommons.org/licenses/by/3.0/). 